\title{
The Effect of Valence and Emotional Intensity on Online Social Support in Facebook
}

\author{
Ahmad M. Abd Al-Aziz \\ Department of Psychology \\ The British University in Egypt (BUE) \\ ahmed.abdelaziz@bue.edu.eg
}

\begin{abstract}
Facebook (FB) has become a powerful tool for analyzing the social behavior of users when they interact online with others in their established network. By using FB, users can publish their personal content, share their own emotions related to their own personal life events and provide their social support using different FB functions provided by its platform. The current study conducted to investigate how do people use the FB functions: "reactions", "comment" and "share" to socially support people who share various valence (positive, negative) and emotional intensity (high positive, low positive, high negative, low negative) posts in response to their life events. This was achieved by presenting a questionnaire to 477 Egyptian students to reveal their preferable FB functions (i.e., reactions, comment and share) when they intend to provide their social support to the person who shares various emotional posts on his timeline (i.e., getting married or engaged, academic or work achievement, death of close family member, major personal illness or injury). The current study findings revealed that the social support on FB influenced by emotional valence of shared posts, as negative posts received more social support compared with shared positive posts. Moreover, the higher positive and negative posts received more social support compared with both low positive and negative posts respectively. Finally, participants preferred using "comment" function compared with "reactions" and "share" functions when they intend to support people who share their emotional posts in response to their major life events.
\end{abstract}

\section{Key words}

Social support; Emotional valence; Emotional intensity, Social Media; Facebook

\section{Introduction}

A friend of the current work's author posted on his Facebook (FB) timeline about the loss of his father. The post was in a black colored image with text overlaid on it. The text revealed some grief sorrow words and he ended this post by showing information about the date and the time of his father's funeral. After a while, i have checked the post and found that many people who are in his social 
network were engaged and provided different kinds of support, some of them shared this post on their timeline, others left some comments enclosed with sorrow words and provided their help, while others just hit the button of reaction (e.g., lightweight like, sad, surprise). If we consider this emotional post as a stimulus that expresses particular feeling toward a certain life event, we will observe that the way people choose to provide their support are vary. Observing these different sorts of support behaviors on FB made me realize how important the topic of social support behavior on social media is to the field of social psychology.

Emotions are central to any interpersonal communication in that another person's show of emotion usually triggers a certain behavior from us. In that sense, individuals have an essential need to share their feelings in response to a certain life event, in one direction, and to receive feedback from the number of people or possible support providers in their environment, in the other direction (Rimé, 2009). Many studies have demonstrated that receiving social support from others gives meaning to individuals' lives by motivating them to give in return, to feel obligated, and to be attached to their social ties (Rook, 1990). In accord to attachment theory, it is in our nature, as newborns, to use emotions to communicate and to create social bonds with our primary caretaker (Planlap, Fitness \& Fehr, 2006). These social bonds are enhanced through a behavior known as social sharing of emotions because the social support we receive from individuals who are in our social network (e.g. friends, neighbors and family) increases our sense of closeness and improve our level of fulfillment of our own interpersonal relationships (Cohen \& Wills, 1985; Diener et al., 1999; Williams, Ware \& Donald, 1981). Sharing victories and success amplifies joy (Langston, 1994) and showing frustrations can help us cope (Pennebaker \& Chung, 2007).

\section{Social sharing of emotions and social support}

The prior works have mostly defined the offline social sharing of emotion as verbal expression in a shared language of an emotion or a feeling — usually after the emotional episode — to others by the person who experienced it (Zech, Rimé, \& Nils, 2004; Rimé, 2009). Available literature of offline interpersonal communication seems to support that social sharing of emotion by individual may trigger strong feelings in the recipient, and recipients often respond with behavior showing some sort of supportiveness such as empathy (Christophe \& Rimé, 1997). With regard to the association between emotion and social sharing, existing research claims that there are a set of parameters that influence the social sharing of emotion from the perspective of the person who shares the emotions with recipient such as latency defined as the period of time that people take to start expressing their feeling after the emotional episode they experienced, recurrence defined as the number of time talking about the same emotional episode, target or to whom did person express his feeling - it might be support if the recipient is in close relationship with him or awkwardness if the person is in distant relationship with him, type of emotion the person shares which reflects that emotional episode (e.g., sad, happy, 
worry) (Rimé, 2009; Singh-Manoux \& Finkenauer, 2001). On the other hand, social support can be broadly defined as the experience of being valued, respected, cared about, sympathized and loved by individuals who are present in one's social network (Gurung, 2006). It occurs through an interactive process and can be related to altruism - a sense of obligation, and the perception of reciprocity (Schwarzer \& Leppin, 1991). The social support could be characterized by the source, which determines from whom individual receives the support, and the type of behavior support provider can take. Social support seems to come from different sources in which individual is affiliated with such as family, friends or any other social groups. With regard to the social support behaviors, a growing body of literature has stated that the most frequently social support actions fall into three categories: emotional, informational, and instrumental support or assistance (House \& Kahn, 1985). Emotional support (e.g., give encouragement) refers to demonstrations of love, caring, esteem and sympathy. Informational assistance is providing some sort of facts or advice; this type of support can also include the feedback about the person's interpretation of any given situation and guidance regarding possible courses of action (Cohen \& McKay, 1984). Instrumental support (e.g., assist with a problem) is offering or supplying behavioral or material assistance with practical tasks. Although these actions are varied, we argue that they may indicate how strength the social support is for both the person who provides the support and the person who receives it. Thus, providing emotional support by showing love and care may reflect lower level of social support compared with providing informational assistance by providing guidance and advice, and this last may reflect lower level of support compared with instrumental support by offering material assistance which enclosed the previous two actions (Lin \& Westcott, 1991).

Social support refers to the experience being valued, respected, cared about, and loved by others who are present in one's life (Gurung, 2006).

As per the aforementioned literature of social sharing and social support relationship, we conclude that it is almost always complex two-ways processes, with people who share their emotion verbally through the face-to-face channel and receiving one or more social support actions in return from the people who are encircled in their social network. As results, the investigation of this relationships requires a conceptual framework that includes activities of the social sharing recipient (i.e. the one who shares his feelings about emotional episode) and the social support provider (i.e. the one who provide social support action(s)) - although these two common terms are misleading since social sharing and social support relationship is usually a mutual interactive process. We use these two terms in the current work for analytic purposes only. In the current work we assume that participants are the ones who provide one of various support actions (providers) for those who enclosed in their social network and share their emotions (recipients) with them. Moreover, most of previous work on social support and social sharing of emotions have been limited to face-to-face or offline communication (Rimé, 2009), and most of the conclusions reached by this work were based on examining the overall 
offline social support received from one or multiple sources, and the type of support behavior received by these sources (Winemiller et al., 1993), and often did not investigate the relationship between valence and emotion intensity of shared emotion in response to life event with the type of received social support behavior.

With pervasive adoption of online Social Networking Sites (SNSs), people are increasingly sharing their emotions in response to their life events with large and diverse groups, including tweets on Twitter and status updates as well as posts on others' timelines on (FB) channels. As result, a growing body of research is investigating the emotional expression, sharing and supportive responses on these sites, and other computer-mediated communication (Bazarova et al., 2015). Research in the area of online social support has demonstrated that perceived support in SNSs or in any online communities has been found to be liked to improve self-efficacy and well-being (Fox \& Jones, 2009; Munson et al., 2010).

Given that social interactions increasingly take place online, the impact of online social support on individual's well-being and the influence of valence and emotional intensity on social support is still not widely understood, the present work examines the influence of valence and emotional intensity of shared posts on the type of social support behavior, an important question is what is the influence of valence and emotional intensity of share post on the online social support behavior?

\section{Social Networking Sites (SNSs)}

SNSs have become powerful and influential tools for communication (Guerrero-Solé, 2018) and they have radically changed the way people interact and communicate. Since their inception, they have attracted millions of users all over the world and many of whom have integrated these sites into their daily practices. SNSs are virtual communities that enable users to connect and interact with others on a particular subject and share information, resources, knowledge and experiences (Chung, Nam \& Koo, 2016; Murray \& Waller, 2007). SNSs allow users not only meet their needs for communication but also other needs such as entertainment, socialization, liking and being liked by others (Bilgin \& Tas, 2018). SNSs allow users to share, post, and discuss interests with similarly interested users regardless of the time and the distance constraints (Jansen et al., 2009), eventually expanding users' social circles and increasing the frequency of interpersonal contacts (Luo \& Zhong, 2015). Through SNSs, people can create a public or semi-public profile, publish their own content, establish permanent connections with other users with whom they share a connection, spread others' content, or express their attitudes toward messages using the like-type functions provided by the platforms. This interactive behavior is traceable (Peng et al., 2016). Therefore, scholars can analyze not only people's activity online but also users' in-network behavior in terms of spreading content and establishing discussions with other users by mentioning and replying (Boyd, Golder, \& Lotan, 2010). What makes social network sites unique is not that they allow individuals to meet strangers, but rather that they enable users to articulate and make visible their social networks. Motivations for sharing on SNSs are diverse (Bazarova et al., 
2015); one possible motivation that has so far received limited consideration is that SNSs are good tools for interpersonal emotion regulation, allowing people to reach both broad and targeted audiences depending on their needs around a particular emotional experience. SNSs are increasingly attracting the attention of academic and industry researchers. Scholars from disparate fields have examined SNSs in order to understand the practices, implications, culture, and meaning of the sites, as well as users' engagement with them (Haythornthwaite, 2005). Among all these sites, FB has become the most relevant sites to social scientists.

\section{Facebook as a leading social media platform}

Since its creation in February 2004, FB has become a spectacular success by creating a massive new domain in which millions of social interactions are played out every day. Park, Kee \& Valenzuela (2009) stated four reasons for using Facebook: socializing, entertainment, self-status seeking, and information seeking. Park \& Lee (2014) found that entertainment, relationship maintenance, selfexpression, and communication are main reasons for using FB. Park et al., (2014) also states that entertainment motivation is the greatest. Nadkarni \& Hofmann in (2012) proposed that FB use derived from to two basic social needs: (1) the need to belong and

2) the need for self-presentation.

In the area of online social support, early studies investigated the ways in which supportive communication evolved in online environments, particularly in comparison with face-to-face contexts (Baym, 1998). In 2016, Burke \& Develin revealed that FB users provide social support actions similar to those in offline communication as hearing about a friend's troubles on FB causes friends to reply with more emotional and supportive online behaviors. In accord with posts with positive feelings, their findings revealed that positive posts receive more likes, and their comments have more positive language. In addition, their findings demonstrated that people share greater amount of both positive and negative emotions when their friends' networks are smaller and denser. However, this work has tended to focus on the emotion valence of shared posts but neglected the influence of emotional intensity on online social support. Inconsistently with the previous work, Yu \& John-Baptiste (2016) showed that most their participants choose to interact with friends or family members in real world to disclose their emotions but not to use SNSs, especially when negative emotions were concerned. They found that participants also reported little benefit to express negative emotions on SNSs in comparison to speaking to friends or family members. Moreover, people also posted significantly more positive than negative information on SNSs. Other previous works investigated that FB use was positively associated with nonmaterial forms of social support such as provision of information, advice, and companionship (Sessions, 2012). Bazarova et al., (2015) investigate how social media properties influences how people share emotions in FB, and their satisfaction after doing so. They demonstrated 
that people's overall satisfaction after sharing emotions in network visible channels is strongly tied to their reply satisfaction. DeAndrea et al., (2012) suggested that social media can be designed and used to enhance individuals' perception of available social support and support networks. Other scholars in the field of social psychology tried to investigate the role of FB use in obtaining social support. In (2104), Kim examined the supportive interactions on FB to understand the role of social media use in obtaining social support and promoting psychological well-being. The study argued a direct relationship between FB use and social support reception. The study results revealed that FB use was the strongest predictor of social support reception, even stronger than the number of strong ties, although its link to life satisfaction was not significant.

To sum up, available empirical studies abundantly investigate the fact that when people experience a FB's post whatever the valence of emotion involved from a person in their online social network, what are the types of their online social support behavior they provide. In addition, the previous work in this area leaves several open questions. One of them, how target people (social support providers) respond to valence emotional posts on FB? Does online social sharing behavior for different emotional valence elicits different forms of online social support behavior? Does the emotional intensity of posts elicit different forms of online social support behavior? We argue that "reactions" button on the FB is similar to emotional support in face-to-face communication as it demonstrates love, caring and sympathy, we argue that giving any sort of reactions about the shared emotion post indicates low level of online social support as one click is enough for any kind of reactions. The "comment" button on FB needs additional action by writing text showing advice, emotional support or provide information, we argue that comment on FB is similar to informational support in face-to-face communication which indicates a higher level of online social support behavior than reactions. Finally, "share" button on FB indicates higher level than "comment" because when commenting on any given post, the post appears on one's timeline. On the other hand, sharing a post, the post not only appears on one's timeline but also goes to one's profile page. This indicates a higher level of online social support behavior. We argue that sharing a post whatever the emotion involved in is similar to instrumental social support which is offering a kind of behavioral or material assistant to the one who shares his emotion. These arguments are based on the literature that investigate the psychological differences between "reactions", "comment" and "share" on FB (Kim \& Yang, 2017). Therefore, the purpose of current study is two-fold. First, this study determines how FB users provide social support when they experienced positive and negative emotional posts in response with major life events. Second, the study investigates the influence of emotional intensity (high positive, low positive, high negative, low negative) of shared posts in response of major life events on the received social support. The current research questions took the following form: What is the form and the level of online social support behavior (e.g. reactions, comment and share) provided by users when they experience different kind of shared emotion posts (positive, negative) about their life events? The current study's question led to ask another question that take the following form: are these online support behaviors change according 
to the emotional intensity of shared emotion posts (high positive, low positive, high negative, low negative) by people on their social network?

Hypothesis have been formulated in the study:

Hypothesis 1: online social support behaviors on FB influenced by the valence shared posts (positive, negative) in response to major life events.

Hypothesis 2: social support behaviors on FB influenced by emotional intensity of shared posts (high positive, low positive, high negative, low negative) in response to major life events.

The current study is significant because the methodology and findings provide a framework on future work in online social support behavior adding to a new and emerging field in social psychology.

\section{Method}

\section{Participants}

An initial sample of 477 graduate and undergraduate students (across 4 years) in the faculty of business administration, economic and political sciences at the British University in Egypt (BUE) started an anonymous questionnaire. Participants were recruited via school campus announcement to participate volunteering. All participants were Internet users and they were active Facebook users for at least three years. No incentives or compensation for participants was provided. The participants' mean age 20.22 years $(S D=1.68)$ ranged from (18 to 25$)$, 344 males $(72.12 \%)$ with mean age 20.22 $(S D=1.68)$ and 133 females $(27.88 \%)$ with mean age $20.21(S D=1.35)$. The demographic features for the current work's sample is shown in Table. 1.

Table. 1 Demographic features of sample $(\mathbf{N}=\mathbf{4 7 7})$

\begin{tabular}{|c|c|c|c|c|c|c|c|c|c|c|}
\hline \multicolumn{11}{|c|}{ Demographic features } \\
\hline & \multicolumn{2}{|c|}{$\begin{array}{c}1^{\text {st }} \text { Year } \\
(N=199)\end{array}$} & \multicolumn{2}{|c|}{$\begin{array}{l}2^{\text {nd }} \text { Year } \\
(\mathrm{N}=91)\end{array}$} & \multicolumn{2}{|c|}{$\begin{array}{c}3^{\text {rd }} \text { Year } \\
(N=141)\end{array}$} & \multicolumn{2}{|c|}{$\begin{array}{l}4^{\text {th }} \text { Year } \\
(N=25)\end{array}$} & \multicolumn{2}{|c|}{$\begin{array}{c}\text { Graduate } \\
(\mathbf{N}=21)\end{array}$} \\
\hline & $\mathrm{N}$ & $\%$ & $\mathrm{~N}$ & $\%$ & $\mathrm{~N}$ & $\%$ & $\mathrm{~N}$ & $\%$ & $\mathrm{~N}$ & $\%$ \\
\hline \multicolumn{11}{|l|}{ Gender } \\
\hline - Male & 122 & 61.31 & 79 & 86.81 & 112 & 79.43 & 14 & 56.00 & 17 & 80.95 \\
\hline - Female & 77 & 38.69 & 12 & 13.19 & 29 & 20.57 & 11 & 44.00 & 4 & 19.05 \\
\hline \multicolumn{11}{|l|}{ Occupation } \\
\hline - Student & 199 & 100 & 91 & 100 & 141 & 100 & 25 & 100 & 21 & 100 \\
\hline - Employee & 0 & 0 & 0 & 0 & 0 & 0 & 0 & 0 & 18 & 85.71 \\
\hline - Unemployed & 199 & 100 & 91 & 100 & 141 & 100 & 25 & 100 & 3 & 14.29 \\
\hline Marital Status & & & & & & & & & & \\
\hline - Married & 0 & 0 & 0 & 0 & 0 & 0 & 0 & 0 & 9 & 42.86 \\
\hline
\end{tabular}

(The Effect of Valence and Emotional Intensity on Online Social Support in Facebook) Ahmad M. Abd Al-Aziz 
- Unmarried

- Divorced

Active FB user (years)

- (3 to 5)

$-(5$ to 10$)$

$-(>10)$

\begin{abstract}
199
\end{abstract}
0

100

$\begin{array}{ll}49 & 24.62\end{array}$

$114 \quad 57.29$

$36 \quad 18.09$

\begin{abstract}
91
\end{abstract}
100

141

0

100

0

25
0

100
0

12

0

57.14

$\begin{array}{ccc}56 & 61.54 & 87 \\ 30 & 32.97 & 45 \\ 5 & 5.49 & 9\end{array}$

61.70

31.91

10

40.00

32.00

$\begin{array}{ll}3 & 14.29\end{array}$

$\begin{array}{lllll}6.38 & 7 & 23.00 & 13 & 61.90\end{array}$

\title{
Design
}

\section{Materials}

We assume that recipients are the people who share the emotional post on FB with the participants who are provide social support actions to them. As there are many life events recipients want to share his/her positive and negative feeling with others in his/her online social network and given the assumption that life events are not uniform in their emotional effects across people (Malhotra \& Mehta, 2008). We have designed a rating scale includes two categories of major positive life events (getting married or engaged, academic or work achievement) and two categories of major negative life-events (death of close family member, major personal illness or injury). Each category comprises of 4 proposed post items. The total number of post items are 16. The main aim of rating scale is to evaluate which positive and negative category of life event rated as high positive or high negative, and which category rated as low positive or low negative. For each post item in each category, participant should rate it as it makes him feel happy or unhappy. For each negative life event items, participant should rate each post item based on valence scale as it makes him feel unhappy by using 3-point rating scale $[1=$ low, $3=$ moderate, $5=$ high. The same rating scale applied for positive post items as each participant should rate each item as it makes him feel happy using 3 -points scale $[1=$ low, $3=$ moderate, $5=$ high]. We handed the list to 30 undergraduate business school students at the British University in Egypt (BUE) in one session, all participants were in the second year with 17 males (57\%) and 13 females (43\%). Their ages ranged from 17 to 18 years $(M=17.30, S D=0.65)$. The rating scale for each item presented in Table. 2. The rating comparison results of positive life events indicate that "getting married or engaged" was positively higher $(M=3.83, S D=1.35)$ than "academic or work achievement" $(M=2.66, S D=1.31), t(29)=3.96, p<0.01$. The rating comparison results of negative life events indicate that "death of close family member" is negatively higher $(M=4.67, S D=$ $0.68)$ than "major personal illness or injury" $(M=2.70, S D=1.44), t(29)=6.61, p<0.01$. Based on the previous results, we assume in the current work's questionnaire that each recipient shares 8 public positive [high positive, low positive] post items and 8 public negative [high negative, low negative] post items on his timeline. participants were incorporated within each kind of online social support actions on FB (reactions, comment and share). Thus, each individual item in the current work's scale referred to one recipient shares his emotion in response to one of his life events, and our participant should indicate one kind of online social supportive actions (reactions, comment, share). Consequently, the questionnaire includes 16 post items that cover two emotional valenced (positive, 
negative) about 4 life events categories (getting married or engaged, academic or work achievement, death of close family member, major personal illness or injury). We used 5-point scale [1 = Never, $2=$ Seldom, 3 = Sometimes, 4 = Often, 5 = Almost always] for each online support actions (reactions, comment, share) to indicate how frequently the participant interact with each post item. Since all participants were Arabic/English bilinguals, the scale was presented in two languages, and the participant was free to respond with whatever language he would prefer.

Table. 2 Mean (SD) for valence and Mean (SD) for arousal for all items used in the current study's questionnaire $(\mathbf{N}=\mathbf{3 0})$

\begin{tabular}{|c|c|}
\hline Category items & $\begin{array}{l}\text { Mean Valence } \\
\text { (SD) }\end{array}$ \\
\hline \multicolumn{2}{|l|}{ 1- Getting married or engaged } \\
\hline $\begin{array}{l}\text { " - "فرحي الأسبوع اللي جاي" - "My wedding will be next week" }\end{array}$ & $3.91(1.31)$ \\
\hline 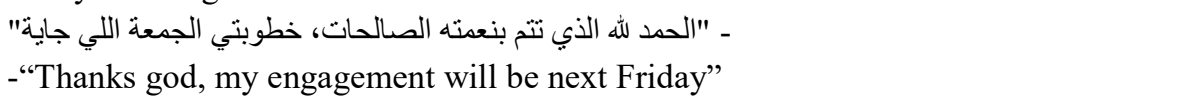 & $3.89(1.37)$ \\
\hline - "الكل معزوم على كتب كتابي في البيت الخميس القادم" & $3.74(1.34)$ \\
\hline $\begin{array}{l}\text { " قراية فنحتي السبت اللي جاي" - "My engagement will be next Saturday" } \\
\text {-"My enged }\end{array}$ & $3.77(1.37)$ \\
\hline \multicolumn{2}{|l|}{ 2- Academic or work achievement } \\
\hline $\begin{array}{l}\text { - "أنخرجت" } \\
\text { - "I’ve been graduated" }\end{array}$ & $2.66(1.43)$ \\
\hline $\begin{array}{l}\text { "- أول يوم ليا في الثنغل النهاردة ادعولي" - The first day at my work, pray for me" } \\
\text { - "Thy }\end{array}$ & $2.68(1.02)$ \\
\hline 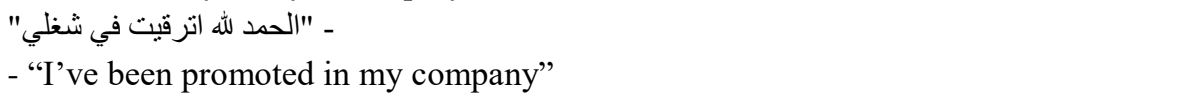 & $2.59(1.35)$ \\
\hline 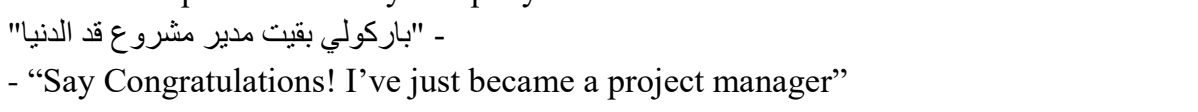 & $2.71(145)$ \\
\hline 3- Death of close family member & \\
\hline 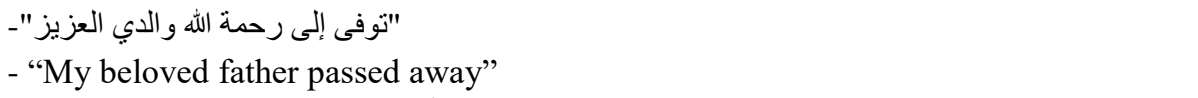 & $4.91(0.68)$ \\
\hline $\begin{array}{l}\text { "توفى إلى رحمة الله أخي صلاة الجنازة عقب صلاة الظهر "My brother passed away; the funeral will be held after Alduhor's prayer" } \\
\text { - "My }\end{array}$ & $4.11(0.78)$ \\
\hline 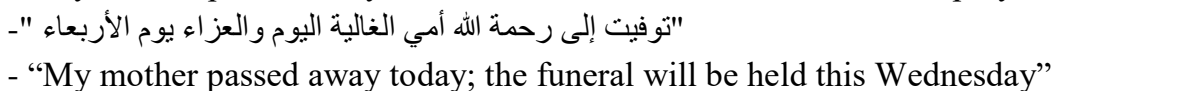 & $4.95(0.67)$ \\
\hline 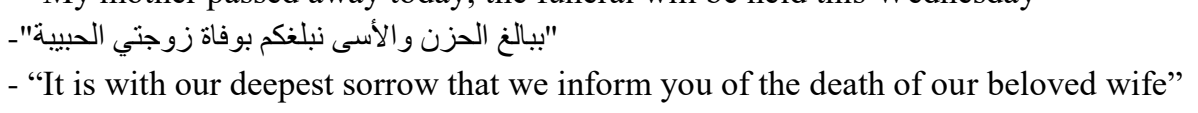 & $4.70(0.57)$ \\
\hline
\end{tabular}




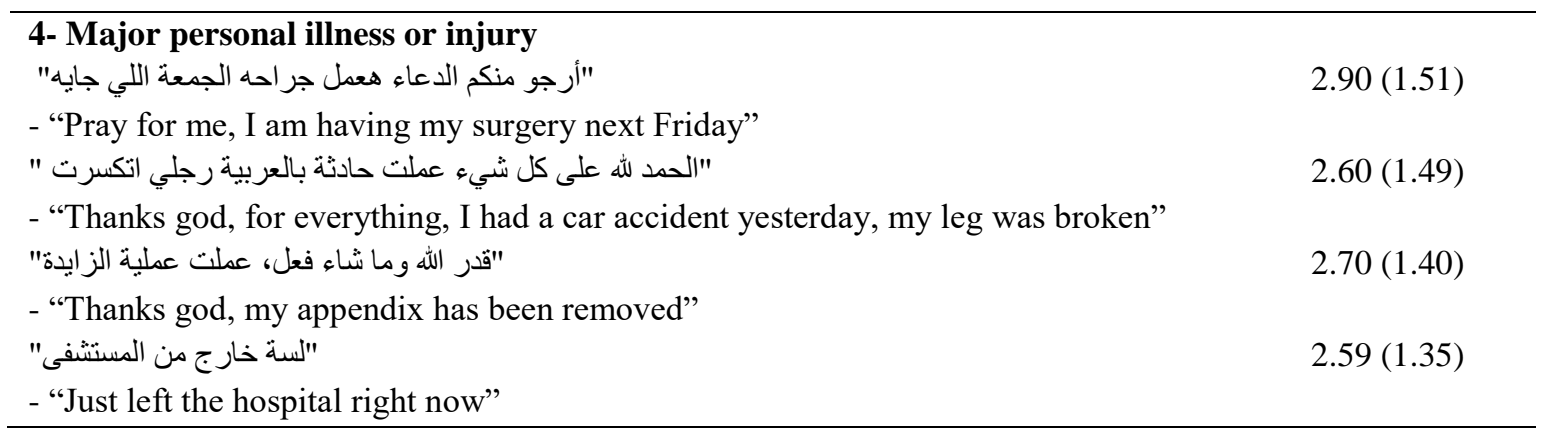

\section{Procedure}

We announced via school campus to participate volunteering in our study. We designed 5 sessions in 14 days long according to the available free times in students' schedules. In each session, participants received a sheet contains all 16 items. Instructions were started by giving appreciation for participating in the current study, then we introduced the main aim of the study. Participants were asked through our designed questionnaire to read each post item carefully, then he/she will find three possible FB functions (reactions, comment, share). Participants were asked to response to each FB function by selecting one option in 5-point scale from "Never", it means that "I am not frequently using this function" to "Almost always", it means "I frequently use this function".

Results

Mean online social support actions on FB (reactions, comment, share) were calculated for the shared four types of valenced posts (high positive, low positive, high negative, low negative) about four different life events. The effect of emotion valence degree and online social sharing actions was analyzed using 4 (emotion valence degree) X 3 (online social sharing actions) within-participants ANOVAs. Significant effects were investigated using T-test. Where sphericity was violated as $p<$ 0.05 and Greenhouse-Geisser $>0.75$. Significant effects were investigated using T-test. The means and standard deviation of online social support actions on FB are given in Table 3. Hence, we calculated the average between the high positive and low positive to get the mean of positive posts, and we calculated the average between the high negative and low negative to get the mean of negative posts.

Table 3. Means (SD) of social support actions on FB for positive and negative posts

\begin{tabular}{lcccc}
\hline & Reactions & Comment & Share & Total \\
\cline { 2 - 5 } Total Positive & $2.75(0.68)$ & $2.79(0.71)$ & $1.77(0.46)$ & $2.44(0.78)$ \\
Total Negative & $1.75(0.47)$ & $3.77(0.66)$ & $2.21(0.68)$ & $2.58(1.06)$ \\
Separate valence & & & & \\
$\quad$ High Positive & $2.50(1.12)$ & $3.55(1.12)$ & $2.06(0.80)$ & $2.70(1.20)$ \\
Low Positive & $3.01(0.82)$ & $2.03(0.83)$ & $1.48(0.50)$ & $2.17(0.97)$ \\
High Negative & $1.73(0.81)$ & $4.16(0.84)$ & $2.90(1.38)$ & $2.93(1.44)$ \\
Low Negative & $1.49(0.50)$ & $3.65(1.12)$ & $1.96(0.83)$ & $2.36(1.26)$
\end{tabular}

(The Effect of Valence and Emotional Intensity on Online Social Support in Facebook) Ahmad M. Abd Al-Aziz 160 
The ANOVA conducted on how participants provide their online social support on FB revealed that there is a significant interaction between the emotion valence of posts (high positive, low positive, high negative, low negative) and the online support actions (reactions, comment, share), $F(3,2)=$ 373.97, $p<0.01$. The result indicates that the online actions taken by participants to provide their social support through FB was affected by the valence and emotional intensity of posts shared by recipients when they experienced different kind of life events. The plot for the interaction between the online social support FB functions and emotional intensity of shared posts by recipients presented in Figure 1.

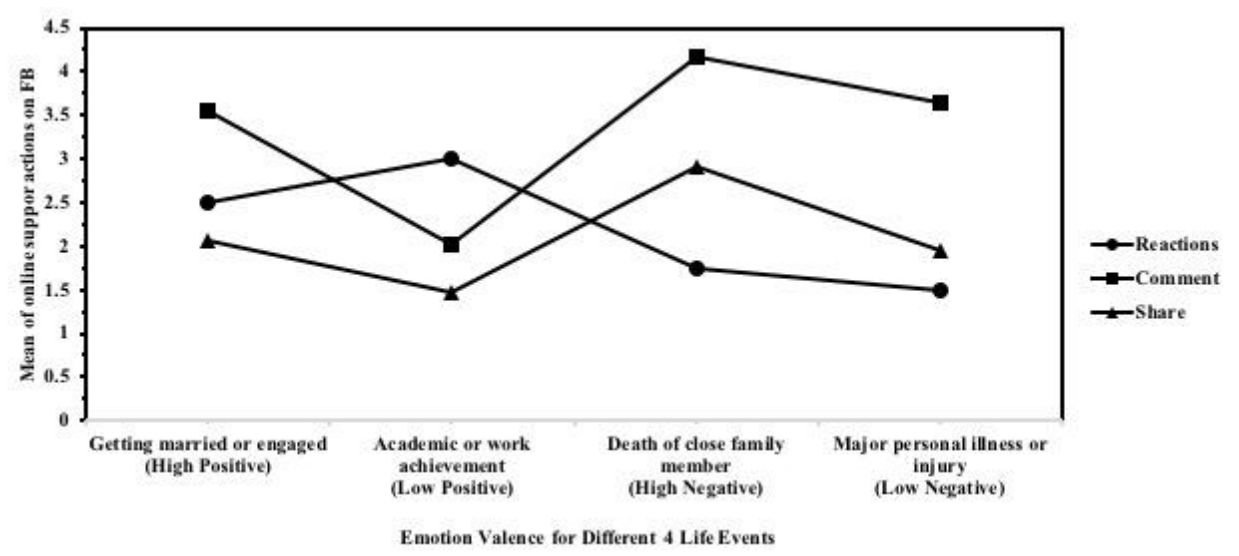

Figure 1. Interaction plot for valence emotional intensity and FB functions

The main effect of emotion valence for different kind of life events was significant $F(3,476)=194.91$ ,$p<0.01$, such that the high negative posts (death of close family member) $(M=2.93, S D=1.44)$ received more social support on FB than the high positive post (getting marriage or engaged) $(M=$ $2.70, S D=1.20$ ) and it received more social support than the low negative post (major personal illness or injury) $(M=2.36, S D=1.26)$, and received more social support than the low positive post (academic or word achievement) $(M=2.17, S D=0.97)$ independent of the social support actions provided by participants on FB. The ANOVA results reveled that the main effect of social support actions on FB provided by participant was significant independent of emotion valence degree (high positive, low positive, high negative, low negative) shared by recipient about the four life events, such that participant preferred using comment $(M=3.35, S D=1.27)$ more than reactions $(M=2.18, S D=$ $1.04)$ and that last is more preferable than using share $(M=2.10, S D=1.06)$ when they provide their support to their recipient. 


\section{Discussion}

the main aim of the current study is to investigate the influence of emotions shared about different life event posts with different emotional valence (high positive, low positive, high negative, low negative) on the social supportive behaviors on FB. This was achieved by presenting a questionnaire to 477 students contains 16 different emotional valenced posts about 4 different major life events (getting married or engaged, academic or work achievement, death of close family member, major personal illness or injury).

Our first hypothesis was that online social support behaviors on FB influenced by the valence of emotional posts (positive, negative) that were shared by people on their FB's social network. We expected participants responded differently by providing different level of social support using different FB functions (reactions, comment, share) when they experienced positive and negative posts. The current work results validated our hypothesis, by showing that total negative posts where their content were about (death of close family member, major personal illness or injury) received more online social support compared with total positive posts where their content were about (getting marriage or engaged, academic or word achievement) independent of the FB functions (reactions, comment, share) that participants preferred to use. Consistent with the assumption of sharing theory applied on the face-to-face communication, as hearing about person's trouble causes others to provide different kinds of social support (Rimé, 2009), the results of the current study revealed that online social support on FB provided the same opportunity for social support as face-to-face communication does when participants experienced negative posts from ones who were in their FB's social network (Indian \& Grieve, 2013; Kim, 2014). Given that FB as one of social media platforms allows individuals to stay connected to a wider range of online social network, FB can be a strongest predictor of social support reception.

The findings provoke an interesting inquiry about the influence of emotion valence for the shared post on the amount of support participants would provide. The findings suggested that the total negative posts received more social support on FB from participants compared with total positive posts. We can think that participants pay more attention to negative life events' posts (death of close family member, major personal illness or injury) more than positive ones (getting marriage or engaged, academic or word achievement). We can interpret the influence of negative shared posts from the perspective of negativity bias, as it suggested that humans tend to put more emphasis on negative content than on positive content in their feelings, judgments, and information-processing tasks (Lang et al., 2007; Rozin \& Royzman, 2001). In other words, negative information tends to elicit stronger and quicker emotional, cognitive, and behavioral responses than neutral or positive information (Baumeister et al., 2001). Several explanations have been proposed to explain negativity bias when it comes to social support exchange outside of FB (e.g., face-to-face communication). One of these explanations focus on the perceptual salience (see Skowronski \& Carlston, 1989 for a review); negative content attracts 
more attention from people than positive content and, as a result, it is more likely to be selected (see Fiske, 1980 for a review). In addition, we think that participants provided more social support when they experienced negative posts on their FB's timeline as the negative posts elicit the sense of altruism more than positive post or hearing good news about people. The altruism is the sense of obligation and the perception of reciprocity (Schwarzer \& Leppin, 1991). This explanation can be reinforced by previous findings when it comes to social support exchange on face-to-face communication, as the altruistic motivation is hypothesized to result from the empathy that is elicited when recipient person is perceived to be in need or in trouble, rather than when this person is perceived to be in good condition (Batson et al., 2011).

Emotional valence of shared emotional posts on FB is not the only factor that needs to be taken into account, but emotional intensity of theses posts also may influence the level of social support provided by participants who experienced these posts on their FB's timeline, even if there has been little research on this aspect. Regarding the emotional intensity, our second hypothesis was that social support behaviors on FB influenced by emotional intensity of shared posts (high positive, low positive, high negative, low negative) about life events. We expected participants responded differently by providing different level of social support using different FB functions (reactions, comment, share) when they experienced high positive, low positive, high negative and low negative posts. The current findings validated our second hypothesis, by showing that high positive posts about (getting married or engaged) received more support compared with low positive posts about (academic or work achievement) independent of the FB functions (reactions, comment, share) that participants preferred to use. Similarly, the current findings show that high negative posts about (death of close family member) received more support compared with low negative posts about (major personal illness or injury) independent of the FB functions (reactions, comment, share) that participants preferred to use. We can think that participants pay more attention to higher emotional intensity posts compared with lower emotional intensity posts. We can interpret the findings theoretically by the urgency effect. Urgency appears to influence behavior (Brehm, 1999). We think that some urges, like those associates with major life event such as death of close family members can be strong as to be irresistible and elicit to stronger behavior responses from those who provide social support. Others, such as "academic or work achievement" can be less urgent to elicit stronger behavioral responses (Baumeister et al., 2001). We think that whatever the intensity of shared emotion by people, whether high or low, participants prioritize them into urgent and non-urgent, and this influence amount of their social support urges one who provide the social support to them in particular way. Our data analysis shows that participants preferred to use the comment more compared with reactions and share in FB to support people who share high positive, high negative and low negative posts (getting married or engaged, death of close family member, major personal illness or injury), and they preferred to use more reactions compared with comment and share when they experienced low positive posts (academic or work achievement). As have been mentioned before: the reaction button is a tool where 
the users can show that they like, enjoy or support the posted content. Also, comments have very much the same function as reactions, though with comments a user can use words to express more of his or her feelings, both positive and negative, this adds more support level more than reactions. We think that participant preferred to use the comment to support people who share their emotions on FB to keep in touch with them in case if those people need help. This explanation can be reinforced by previous work findings of Spottswood \& Wohn (2019), their study surveyed 260 Facebook users to investigate how people are using "reaction" buttons to respond to others' posts about negative topics such as traumatic life situations and interpersonal crises. Results suggest that users do not perceive the reaction buttons as adequate tools to help them interact with people who share these highly emotional posts.

\section{Conclusion}

the current study suggests that valence and emotional intensity of shared posts in response to major life events influence the social support behavior for people on Facebook. In terms of emotional valence, the results of the current study suggest that the negative posts that people share in response to two of their life events (death of close family members, major personal illness and injury) received more social support compared with positive posts that people share in response to two of their life events (getting married or engaged, academic or work achievement). On the other hand, the results of current study suggest that the emotional intensity of posts influences the social support behavior for people on Facebook, as the shared high valenced positive posts in response to (getting married or engaged) received more social support compared with the shared low valenced positive posts in response to (academic or work achievement), and the shared high valenced negative posts in response to (death of close family members) received more social support compared with the shared low valenced negative posts in response to (major personal illness or injury). Moreover, the current study results suggest that participants prefer using the "comment" functions compared with "reaction" and "share" functions when they tend to provide their social supports when they experienced (high positive, high negative, low negative) posts on Facebook. Further research could continue to examine more variables that may influence the social support behavior in Facebook such as the social ties between people on their offline and online social network. 


\section{Reference}

Batson, C. D., Ahmad, N., \& Lishner, D. A. (2011). Empathy and altruism. In Lopez, S. J. \& Snyder, C. R. (Eds.). Oxford handbook of positive psychology, 2nd Edition (pp. 417-426). New York, NY: Oxford University Press.

Baumeister, R. F., Bratslavsky, E., Finkenauer, C., \& Vohs, K. D. (2001). Bad is stronger than good. Review of General Psychology,5(4), 323-370.

Baym, N. K. (1998). The emergence of on-line community. In S. G. Jones (Ed.), Cybersociety 2.0: Revisiting computer-mediated communication and community (pp. 35-68). Thousand Oaks, CA: SAGE Publications.

Bazarova, N., Choi, Y., Sosik, V., Cosley, D., \& Whitlock., J. (2015). Social sharing of emotions on Facebook: Channel differences, satisfaction, and replies, The $18^{\text {th }}$ ACM conference on computer-supported cooperative work and social computing (CSCW 2015), Vancouver, BC, Canada. 154-164.

Bilgin, O., \& Tas, I. (2018). Effects of perceived social support and psychological resilience on social media addiction among university students. Universal journal of educational research, 6, 751758, doi://10.13189/ujer.2018.060418

Boyd, D., Golder, S., \& Lotan, G. (2010). Tweet, tweet, retweet: Conversational aspects of retweeting on twitter. Proceedings of the Annual Hawaii International Conference on System Sciences, Honolulu, doi:10.1109/HICSS.2010.412

Brehm, J. (1999). The intensity of emotion. Personality and social psychology review, 3, 2-22.

Burke, M., \& Develin, M. (2016). Once more with feeling: Supportive responses to social sharing on Facebook. The 19th ACM conference on computer-supported cooperative work and social computing, San Francisco, USA, doi: http://dx.doi.org/10.1145/2818048.2835199

Christophe, V. \& Rimé, B. (1997). Exposure to the social sharing of emotion: Emotional impact, listener responses and secondary social sharing. European journal of social psychology, 27 (1), $37-54$.

Chung, N., Nam, K., \& Koo, C. (2016). Examining information sharing in social networking communities: Applying theories of social capital and attachment. Journal of Telematic Informatics, 33, 77-91.

Cohen, S. \& McKay, G. (1984). "Social support, stress and the buffering hypothesis: A theoretical analysis.", Handbook of psychology and health. In Baum, A., Taylor, S. E., \& Singer, J. E., (Eds). 253-67, Hillsdale, NJ: Lawrence Erlbaum

Cohen, S., \& Wills, T. (1985). Stress, social support, and the buffering hypothesis. Psychological Bulletin, 98, 310-357.

(The Effect of Valence and Emotional Intensity on Online Social Support in Facebook) Ahmad M. Abd Al-Aziz 165 
DeAndrea, D. C., Ellison, N. B., LaRose, R., Steinfield, C., \& Fiore, A. (2012). Serious social media: On the use of social media for improving students' adjustment to college. Internet and higher education, 15, 15-23.

Diener, E., Suh, E., Lucas, R., \& Smith, H. (1999). Subjective well-being: Three decades of progress. Psychological Bulletin, 125, 276-302.

Fiske, S. T. (1980). Attention and weight in person perception: The impact of negative and extreme behavior. Journal of personality and social psychology,38(6), 889-906.

Fox, S., \& Jones, S. (2009). The social life of health information. Washington, DC: Pew Internet \& American Life Project, 10-12.

Guerrero-Solé, F. (2018). Interactive behavior in political discussions on Twitter: politicians, media, and citizens' patterns of interaction in the 2015 and 2016 electoral campaigns in Spain. Social Media + Society, doi: 10.1177/2056305118808776.

Gurung, R.A.R. (2006). Health Psychology: A Cultural Approach. Belmont CA: Thomson Wadsworth.

Haythornthwaite, C. (2005). Social networks and Internet connectivity effects. Information, Communication, \& Society, 8(2), 125-147.

House, J., \& Kahn, R. (1985). Measures and concepts of social support. In Cohen, S. \& Syme, S. L. (Eds), Social support and health, 83-108, San Diego, CA: Academic Press.

Indian, M. \& Grieve, R. (2013). When Facebook is easier than face-to-face: Social support derived from Facebook in socially anxious individuals. Personality and individual differences, 59, 102106.

Jansen, B.J., Zhang, M., Sobel, K. \& Chowdury, A. (2009). Twitter power: Tweets as electronic word of mouth. Journal of American society information science technology, 60, 2169-2188.

Kim, H. (2014). Enacted social support on social media and subjective well-being. International journal of communication, 8, 2340-2342.

Kim, C. \& Yang, S. (2017). Like, comment, and share on Facebook: How each behavior differs from the other. Public relations review, 43, 441-449. doi:// 10.1016/j.pubrev.2017.02.006

Langston, C. (1994). Capitalizing on and coping with daily-life events: Expressive responses to positive events. Journal of personality and social psychology, 67, 1112-1125. doi://10.1037/0022-3514.67.6.1112

Lang, A., Park, B., Sanders-Jackson, A. N., Wilson, B. D., \& Wang, Z. (2007). Cognition and emotion in TV message processing: How valence, arousing content, structural complexity and information density affect the availability of cognitive resources. Media psychology, 10(3), 317338.

Lin, N. \& Westcott, J. (1991). Marital engagement/disengagement social networks, and mental health. In Eckenrode, J. (Eds), The Social context of coping, 213-37, New York: Plenum. 
Luo, Q. \& Zhong, D. (2015). Using social network analysis to explain communication characteristics of travel-related electronic word-of-mouth on social networking sites. Tourism Management, 46, 274-282.

Malhotra, S.K., Mehta V. (2008). Role of stressful life events in induction or exacerbation of psoriasis and chronic urticaria. Indian journal of dermatology, venereology and leprology, 74, 594-599.

Munson, S.A., Lauterbach, D., Newman, M.W. \& Resnick, P. (2010). Happier together: integrating a wellness application into a social network site. International conference on persuasive technology, Springer, 27-39.

Murray, K.E. \& Waller, R. (2007). Social networking goes abroad. International journal of education, 16, 56-59.

Nadkarni, A., \& Hofmann, S.G. (2012). Why do people use Facebook? Personality and individual differences, 52(3), 243-249.

Park, N., Kee, K. F., \& Valenzuela, S. (2009). Being immersed in social networking environment: Facebook groups, uses and gratifications, and social outcomes. Cyberpsychology \& behavior, 12(6), 729-733.

Park, N., \& Lee, S. (2014). College students' motivations for Facebook use and psychological outcomes. Journal of broadcasting \& electronic media, 58(4), 601-620.

Peng, T.-Q., Liu, M., Wu, Y., \& Liu, S. (2016). Follower-followee network, communication networks, and vote agreement of the U.S. members of congress. Communication research, 43, 996-1024. doi://10.1177/0093650214559601

Pennebaker, J. \& Chung. C. (2007). Expressive writing, emotional upheavals, and health. Handbook of health psychology, 263-284.

Planlap, S., Fitness, J. \& Fehr, B. (2006). Emotion in theories of close relationships. In Vangelisti, A. \& Perlman, D. (Eds), Cambridge handbook of personal relationships, Cambridge: Cambridge University Press, 369-84.

Rimé, B. (2009). Emotion elicits the social sharing of emotion: Theory and empirical review. Emotion Review, 1, 60-85.

Rook, K. S. (1990). Social relationships as a source of companionship: Implications for older adult's psychological well-being. In Sarason, B. R., Sarason, I. G. \& Pierce, G. R. (Eds.), Social support: An interactional view, 221-250. New York: Wiley.

Rozin, P., \& Royzman, E. B. (2001). Negativity bias, negativity dominance, and contagion. Personality and social psychology review,5(4), 296-320.

Schwarzer, R., \& Leppin, A. (1991). Social support and health: A theoretical and empirical overview. Journal of Social and Personal Relationships, 8, 99-127.

Sessions, L. (2012). Friends in all the right places: Social resources and geography in the age of social network sites (Doctoral dissertation). University of Pennsylvania, Philadelphia, PA. 
Singh-Manoux, A., \& Finkenauer, C. (2001). Cultural variations in social sharing of emotions: An intercultural perspective on a universal phenomenon. Journal of cross-cultural psychology, 32, 647-661.https://doi.org/10.1177/002202210103200600

Skowronski, J. J., \& Carlston, D. E. (1989). Negativity and extremity biases in impression formation: A review of explanations. Psychological bulletin,105(1), 131-142.

Spottswood, E. \& Wohn, D., Y. (2019). Beyond the "Like": How people respond to negative posts on Facebook? Journal of broadcasting \& electronic media, 63(2), 250 -267.

Williams, A., Ware, J., \& Donald, C. (1981). A model of mental health, life events, and social supports applicable to general populations. Journal of health and social behavior, 22, 324-333.

Winemiller, D. R., Mitchell, M. E., Sutliff, J., \& Cline, D. (1993). Measurement strategies in social support: A descriptive review of the literature. Journal of clinical psychology, 49, 638-648.

$\mathrm{Yu}$, H., \& John-Baptiste, S. (2016). Annual international conference on cognitive and behavioral psychology. doi://10.5176/2251-1865_CBP16.20.

Zech, E., Rimé, B. \& Nils, F. (2004) Social sharing of emotion, emotional recovery, and interpersonal aspects. The Regulation of Emotion, 157-185. 